\title{
The supra-iliac anterior quadratus lumborum block: a cadaveric study and case series
}

\section{Le bloc du muscle carré des lombes antérieur par approche supra-iliaque : une étude cadavérique et une série de cas}

\author{
Hesham Elsharkawy, MD, MBA, MSc • Kariem El-Boghdadly, MBBS, BSc, FRCA, EDRA, MSc • \\ Theresa J. Barnes, MD, MPH • Richard Drake, PhD • Kamal Maheshwari, MD, MPH • \\ Loran Mounir Soliman, MD • Jean-Louis Horn, MD • Ki Jinn Chin, MD, FRCPC
}

Received: 9 July 2018/Revised: 10 December 2018/Accepted: 10 December 2018/Published online: 11 March 2019

(C) Canadian Anesthesiologists' Society 2019

\begin{abstract}
Purpose The local anesthetic injectate spread with fascial plane blocks and corresponding clinical outcomes may vary depending on the site of injection. We developed and evaluated a supra-iliac approach to the anterior quadratus lumborum (QL) block and hypothesized that this single injection might successfully block the lumbar and sacral plexus in cadavers and provide analgesia for patients undergoing hip surgery.
\end{abstract}

Permission to use images was obtained from the Cleveland Clinic Department of Art Photography.

Electronic supplementary material The online version of this article (https://doi.org/10.1007/s12630-019-01312-z) contains supplementary material, which is available to authorized users.

H. Elsharkawy, MD, MBA, MSc ( $₫) \cdot$ K. Maheshwari, MD, $\mathrm{MPH}$

Departments of General Anesthesia and Pain Management, Outcomes Research, Anesthesiology Institute, Cleveland Clinic, 9500 Euclid Avenue, Mail Code E31, Cleveland, OH 44195, USA

e-mail: elsharh@ccf.org

Anesthesiology CCLCM of Case Western Reserve University, Cleveland, OH, USA

K. El-Boghdadly, MBBS, BSc, FRCA, EDRA, MSc Department of Anaesthesia, Guy's \& St Thomas' NHS

Foundation Trust, London, UK

King's College London, London, UK

T. J. Barnes, MD, MPH

Department of Anesthesiology, Emory University School of Medicine, Atlanta, GA, USA
Methods Ultrasound-guided bilateral supra-iliac anterior QL blocks were performed with $30 \mathrm{~mL}$ of India ink dye in six fresh adult cadavers. Cadavers were subsequently dissected to determine distribution of the dye. In five patients undergoing hip surgery, a unilateral supra-iliac anterior QL block with $25 \mathrm{~mL}$ ropivacaine $0.5 \%$ followed by a continuous catheter infusion was performed. Patients were clinically assessed daily for block efficacy.

Results The cadaveric injections showed consistent dye involvement of the majority of the branches of the lumbar plexus, including the femoral nerve, lateral femoral cutaneous nerve, ilioinguinal nerve, and iliohypogastric nerve. The majority of cadaveric specimens (83\%) also exhibited thoracic paravertebral spread of dye to the T10 level. No specimens showed L5 or sacral nerve root staining or caudal spread below L5. All patients had

\section{R. Drake, $\mathrm{PhD}$}

Cleveland Clinic Lerner College of Medicine, Cleveland, OH, USA

L. M. Soliman, MD

Departments of General Anesthesia and Pain Management, Anesthesiology Institute, Cleveland Clinic, Cleveland, OH, USA

J.-L. Horn, MD

Department of Anesthesiology, Perioperative and Pain Medicine, Stanford, CA, USA

K. J. Chin, MD, FRCPC

Department of Anesthesia, Toronto Western Hospital, University of Toronto, Toronto, ON, Canada 
effective analgesia for total hip surgery and a T11-L3 sensory level following the initial bolus of local anesthetic as well as during the period of continuous catheter infusion.

Conclusion This cadaveric study and case series show that a supra-iliac approach to the anterior $Q L$ block involved T10--L3 nerve territories and dermatomal coverage with no sacral plexus spread. This technique may have clinical utility for analgesia in hip surgery.

\section{Résumé}

Objectif La diffusion de l'anesthésique local injecté lors de la réalisation d'un bloc du fascia et les résultats cliniques qui en découlent peuvent varier selon le site d'injection. Nous avons mis au point et évalué une approche suprailiaque pour la réalisation d'un bloc du muscle carré des lombes antérieur (quadratus lomburum) et émis l'hypothèse que cette injection unique pourrait suffire à bloquer les plexus lombaire et sacral de cadavres, offrant ainsi une analgésie aux patients subissant une chirurgie de la hanche. Méthode Des blocs bilatéraux du muscle carré des lombes antérieur ont été réalisés par approche supra-iliaque sous échoguidage à l'aide de $30 \mathrm{~mL}$ de teinture d'encre de Chine sur six cadavres adultes frais. Les cadavres ont par la suite été disséqués afin de déterminer la diffusion de la teinture. Nous avons réalisé un bloc unilatéral du muscle carré des lombes antérieur par approche supra-iliaque avec une solution de $25 \mathrm{~mL}$ de ropivacaïne 0,5\%, suivie d'une perfusion continue via cathéter, chez cinq patients subissant une chirurgie de la hanche. Une évaluation clinique quotidienne des patients a été réalisée afin de déterminer l'efficacité du bloc.

Résultats Les injections sur les cadavres ont permis d'observer une diffusion constante de la teinture dans la majorité des branches du plexus lombaire, y compris dans le nerf fémoral, le nerf fémoral cutané latéral, le nerf ilioinguinal et le nerf ilio-hypogastrique. Une diffusion paravertébrale thoracique de la teinture jusqu'au niveau T10 a également été retrouvée dans la majorité des spécimens cadavériques (83\%). Aucune coloration au niveau de la racine $L 5$ ou des nerfs sacrés n'a été observée chez les spécimens, ni aucune diffusion caudale au-dessous de L5. Tous les patients ont reçu une analgésie efficace pour une arthroplastie totale de la hanche et obtenu un bloc sensitif au niveau T11-L3 après l'injection du bolus initial d'anesthésique local ainsi qu'au cours de la période de perfusion continue.

Conclusion Cette étude cadavérique et cette série de cas montrent qu'une approche supra-iliaque pour réaliser un bloc du muscle du carré des lombes antérieur est parvenue à atteindre les territoires nerveux T10--L3 et avec couverture de ces dermatomes et ce, sans diffusion au niveau du plexus sacré. Cette technique pourrait avoir une utilité clinique pour l'analgésie en cas de chirurgie de la hanche.

The ultrasound-guided quadratus lumborum (QL) block is a regional anesthetic technique with many described approaches ${ }^{1}$ : the lateral QL (QL1) block, ${ }^{2}$ the posterior QL (QL2) block, ${ }^{3}$ and the anterior QL (transmuscular) block. ${ }^{4}$ While initially described as an analgesic modality for abdominal surgery, ${ }^{2,5-12}$ the anterior QL block has also been used in hip surgery case reports. ${ }^{13-16}$ Recent evidence of the anterior QL block performed at the L3-L4 level in cadavers has shown spread to branches of the lumbar plexus, which may account for the analgesia observed after hip surgery. ${ }^{17-19}$ To provide complete regional analgesia after hip surgery, blockade of the branches of both lumbar and sacral plexuses is required, although there remains no single technique that reliably accomplishes this.

The nerves of the lumbar plexus, including the femoral, lateral femoral cutaneous, and obturator nerves, lie within the psoas major muscle. These nerves then variably exit the psoas muscle to lie inside the iliopsoas compartment, between the iliacus and psoas major muscles. The caudal extension of this anatomical space contains the sacral plexus. $^{20}$ The psoas and iliacus muscles are encased by the fascia iliaca. The fascia iliaca fuses superiorly with the anterior thoracolumbar fascia (transversalis fascia) that encases both the QL and the psoas muscles. ${ }^{21}$

The sacral plexus originates from the lumbosacral trunk (L4-L5) and the anterior rami of the S1-S3 nerve roots. The lumbosacral trunk is found between the iliacus and the psoas major, within the iliopsoas compartment ${ }^{21}$; more caudally, it lies between the piriformis muscle fascia and the pelvic presacral fascia. The tissue planes situated between the QL and psoas muscles in the abdomen, between the psoas and iliacus muscles in the pelvis, and between the piriformis and pelvic presacral fascia in the pelvis are anatomically continuous. Therefore, this provides a potential route for local anesthetic spread to block the branches of the lumbar and sacral plexi (Figs 1 A, B).

We thus developed and evaluated a supra-iliac approach to the anterior QL block that is performed at a lower level than traditional anterior QL block approaches. We hypothesized that this single injection might successfully block the lumbar and sacral plexi in cadavers and provide analgesia in patients undergoing hip surgery. 
Fig. 1 A Illustration of the key nerves and muscles of the posterior abdominal wall. $\mathrm{FN}=$ femoral nerve; $\mathrm{LFC}=$ lateral femoral cutaneous nerve; $\mathrm{QL}=$ quadratus lumborum; $\mathrm{TP}=$ transverse process. $\mathrm{B}$

Illustration of a cross section at L3 level depicting the relevant nerves, muscles, and fasciae
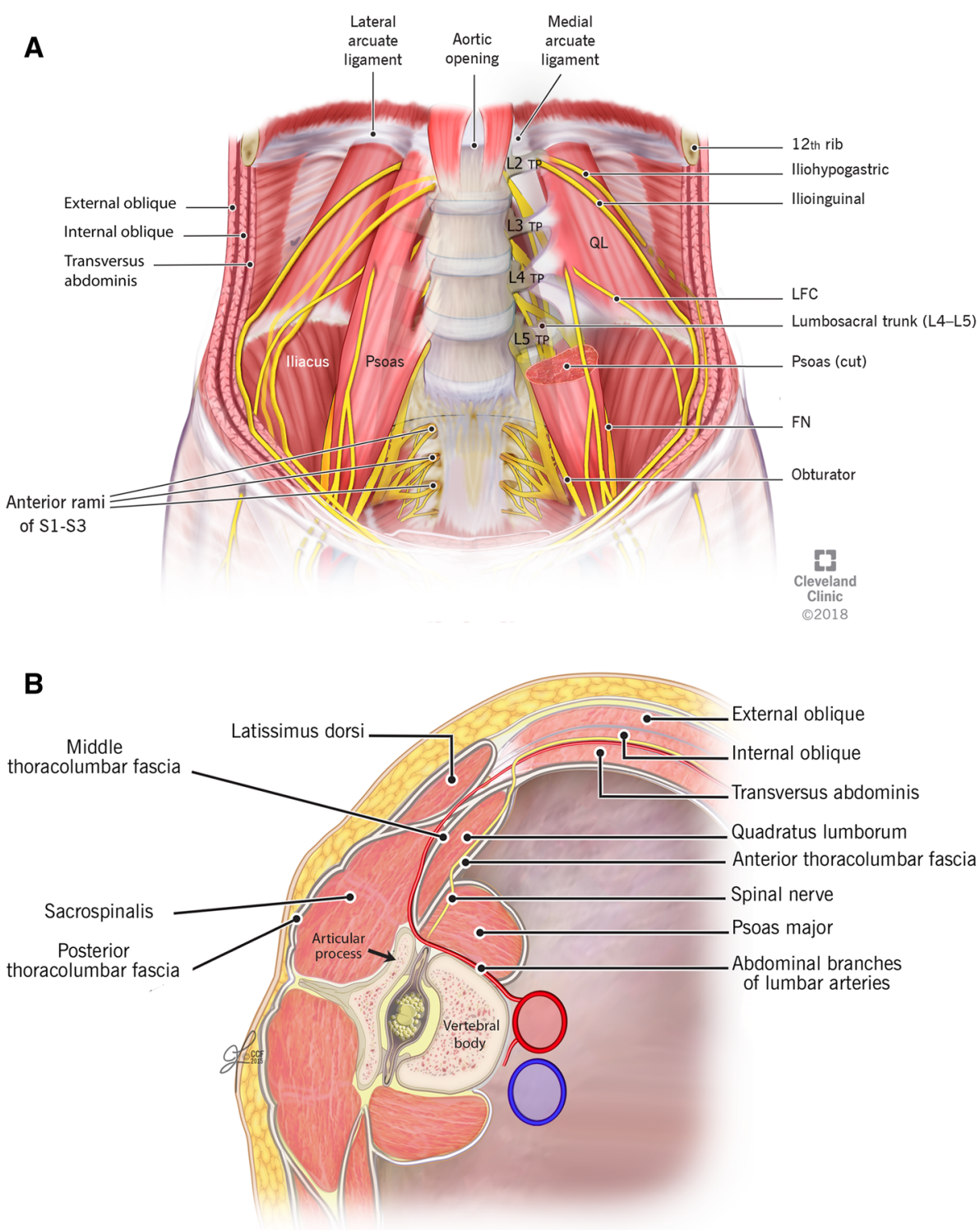

\section{Methods}

Institutional review board approval was granted for the case series (Institutional Review Board number 18-168, 12 February 2018) and a waiver granted for the cadaveric study.

\section{Cadaveric subjects}

Six fresh adult cadavers were chosen to represent a variable range of body habitus both in terms of body mass index and gender. Cadavers with known lumbar deformities, or previous spine or hip surgery were excluded from the study. All cadavers were maintained at room temperature for at least $12 \mathrm{hr}$ before injections. Bilateral ultrasoundguided supra-iliac anterior QL blocks were performed on each cadaver in the Cleveland Clinic cadaver laboratory by two investigators (H.E. and L.M.).

Supra-iliac anterior QL block technique

Blocks were performed in the prone position for all cadavers, and in the lateral position for all patients. A curvilinear transducer-SonoSite S-Nerve (National Ultrasound, Duluth, GA, USA) or Venue 40 low frequency (GE Healthcare, Norcross, GA, USA) - was first placed in a parasagittal orientation $3-4 \mathrm{~cm}$ lateral to the midline and over the sacrum to identify the tip of the L5 transverse process. The probe was then rotated into a transverse orientation with slight medial and caudal angulation to obtain a transverse oblique view at L5 transverse process. The ultrasound probe was further tilted 
A

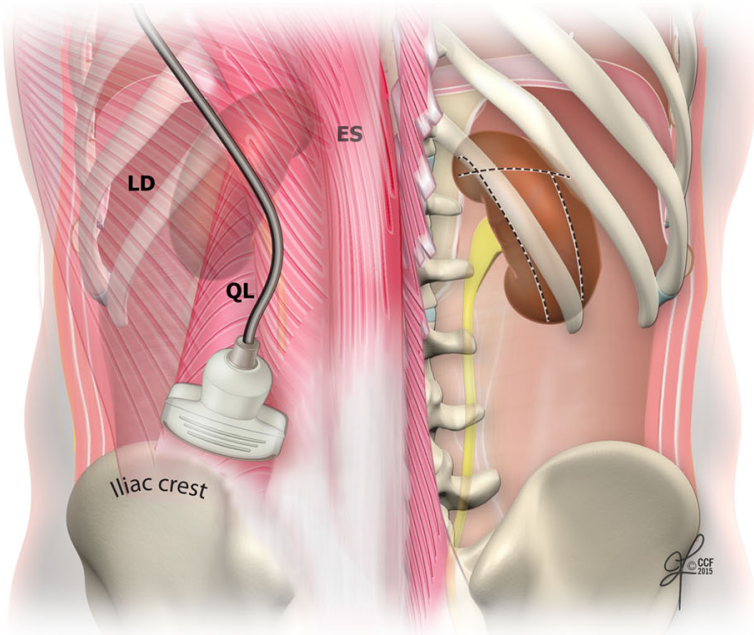

B

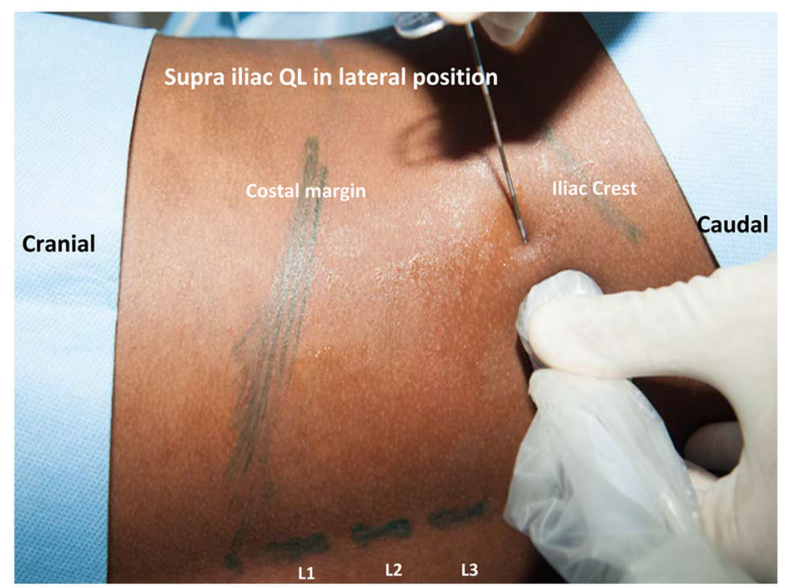

C

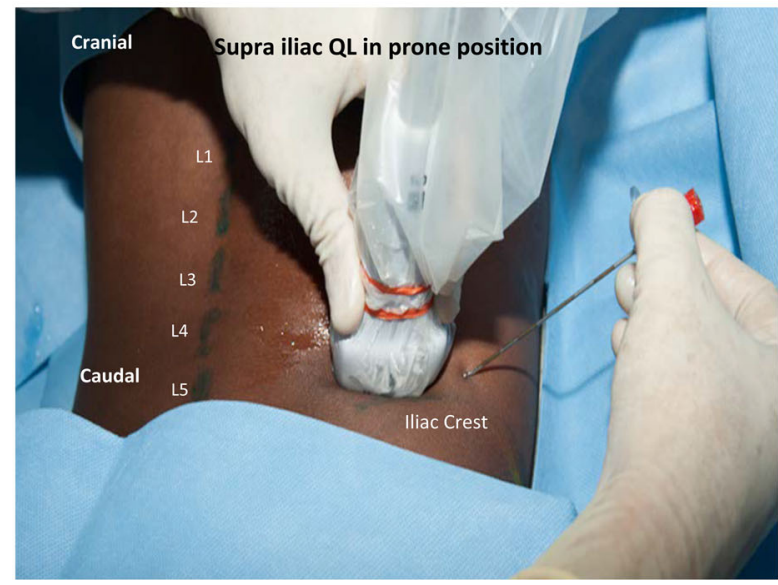

Fig. 2 A Illustration showing ultrasound transducer position when performing a supra-iliac anterior quadratus lumborum block. ES = erector spinae muscle; $\mathrm{LD}=$ latissmus dorsi muscle; $\mathrm{QL}=$ quadratus lumborum muscle. B, C External photos showing the ultrasound probe location, external landmarks in different positions, and the needle in a volunteer

so the lateral end of the ultrasound probe was more cranial than the medial side of the probe to avoid the acoustic shadow of the iliac crest (Fig. 2 A). This served to direct

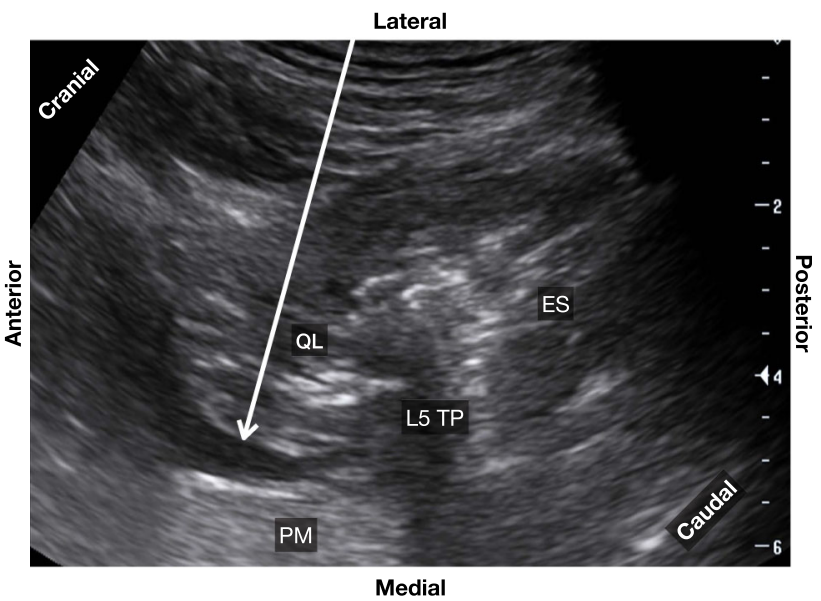

Fig. 3 Ultrasound image showing sonographic landmarks and needle approach (white arrow) to the supra-iliac QL block. ES = erector spinae muscle; L5 TP = L5 transverse process acoustic shadow; PM = psoas major muscle; QL = quadratus lumborum muscle; local anesthetic between QL and PM

the angle of the probe, and thus the sonographic beam, caudally into the pelvis (Figs $2 \mathrm{~B}, \mathrm{C}, \mathrm{D}$ ). It also allowed the latissimus dorsi aponeurosis (laterally), QL muscle, psoas major muscles, and L5 transverse process (medially) to be visualized (Fig. 3). An $8 \mathrm{~cm}, 17-\mathrm{G}$ echogenic Tuohy needle (Pajunk, Geisingen, Germany) was advanced in plane in a lateral-to-medial direction, through the latissmus dorsi aponeurosis and QL muscle to position the tip between the QL and psoas major muscles close to the transverse process. Correct needle tip position was confirmed by injecting $2-3 \mathrm{~mL}$ of sodium chloride $0.9 \%$. Spread was deemed appropriate when injectate was seen between QL and psoas major muscles and tracking medially towards the L5 transverse process (Figs 3, 4 A, B). In the cadaver specimens, $30 \mathrm{~mL}$ methylcellulose $0.5 \%$ with $0.5 \mathrm{~mL}$ India ink was then injected on one side and then the block was repeated on the contralateral side.

In the hip surgery patients, $20 \mathrm{~mL}$ ropivacaine $0.5 \%$ was injected. After this, an Arrow ${ }^{\circledR}$ FlexTip ${ }^{\circledR}$ Catheter (Teleflex, Research Triangle Park, NC, USA) was advanced $4 \mathrm{~cm}$ beyond the needle tip. A further $5 \mathrm{~mL}$ ropivacaine $0.5 \%$ was injected through the catheter to confirm appropriate fluid spread and correct positioning of the catheter tip. The catheters were tunneled medially and secured with sterile adhesive dressing to increase the distance between the surgical incision and the catheter insertion site to reduce the risk of dislodgement.

Cadaveric anatomic dissection

Two hours after injection, the cadavers were dissected bilaterally in layers, from superficial (posterior) to deep 

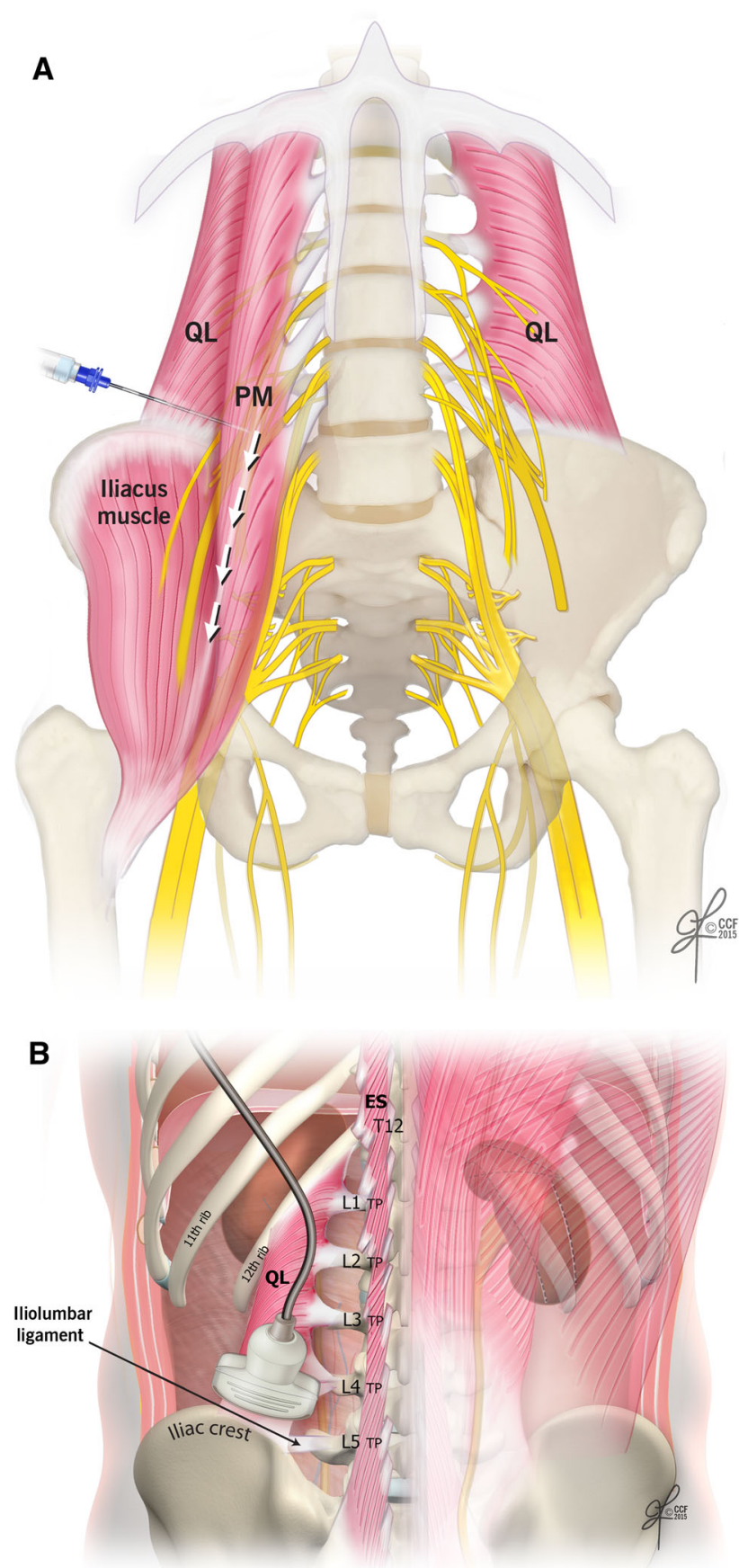

Fig. 4 A, B Illustration showing the needle approach and spread of injectate following a supra-iliac anterior QL block. ES = erector spinae muscle; $\mathrm{PM}=$ psoas major muscle; $\mathrm{QL}=$ quadratus lumborum muscle; TP $=$ transverse process. White arrows representing caudal spread of the local anesthetics

(anterior), by an anatomist (R.D.) to map the extent of dye spread.

A vertical midline incision was made from the 5th thoracic spinous process to the level below the iliac crest. A transverse incision was then made below the iliac crest, extending from the midline to the mid-axillary line bilaterally. A flap of skin and subcutaneous fascia was raised, exposing the latissimus dorsi muscle and aponeurosis. This muscle, along with the posterior layer of the thoracolumbar fascia, was reflected laterally allowing visualization of the erector spinae muscle, which was then removed. This revealed the underlying middle thoracolumbar fascia, lumbar transverse processes, intertransverse ligaments, and the QL muscle. The craniocaudad and lateral extent of dye spread posterior to the QL muscle was evaluated.

Subsequently, the ribs were removed around the articular surface of the transverse processes from T5-T12 and the transverse processes, the intercostal muscles and the levatores costarum muscles were then removed to visualize staining of the thoracic paravertebral spaces and the thoracoabdominal nerves where they emerged from the intervertebral foramina.

Next, the QL muscle was retracted to expose the psoas major muscle, allowing visualization of any potential staining of the anterior thoracolumbar fascia and psoas muscle. The psoas muscle was then retracted laterally to visualize any staining of the lumbar spinal nerves where they emerged from the intervertebral foramina.

Upon completion of the posterior dissection, each cadaver was placed in a supine position and a transverse mid-abdominal incision was made. The rectus abdominis muscles and lateral abdominal wall muscles were removed and the abdominal contents were retracted laterally to allow access to the retroperitoneal space and identification of the psoas major muscle, iliolumbar ligament, the iliac crest, iliacus muscles, and the anterior surface of the QL muscle. The QL muscle was identified at its attachment to the iliac crest. To identify the proximal lumbar plexus from the anterior aspect, the QL and psoas major muscles were retracted medially and then partially removed. The tissue plane between the psoas major and iliacus muscle was dissected to identify the femoral nerve and lateral femoral cutaneous nerve of the thigh on the anterior surface of the iliacus muscle, and the obturator nerve where it descends on the postero-medial side of the psoas major and the iliacus. The lumbosacral trunk (L4-L5) descends medial to the obturator nerve to join the anterior rami of S1-S3 in the pelvis. ${ }^{21}$ To identify the sacral nerve roots (S1-S4) as they exit sacral foramina, the piriformis muscle was retracted laterally and caudally to the iliopsoas tendon, exposing the nerve roots.

Throughout the dissection, key anatomical structures, including the QL muscle, iliacus muscle, the iliopsoas compartment, terminal branches of lumbar plexus, and the lumbosacral trunk were photographed and documented. Positive staining of nerves was defined as direct uptake of ink by the nerves or the surrounding tissue. 
Fig. 5 Cadaveric specimen following a left supra-iliac anterior QL block. Dye staining can be seen to involve the lower thoracic nerves (T10-T12), the diaphragm, lung, and the paravertebral space as high as T10. The QL muscle and the ilioinguinal and iliohypogastric nerves are also heavily stained. $\mathrm{PV}=$ paravertebral; $\mathrm{QL}=$ quadratus lumborum muscle

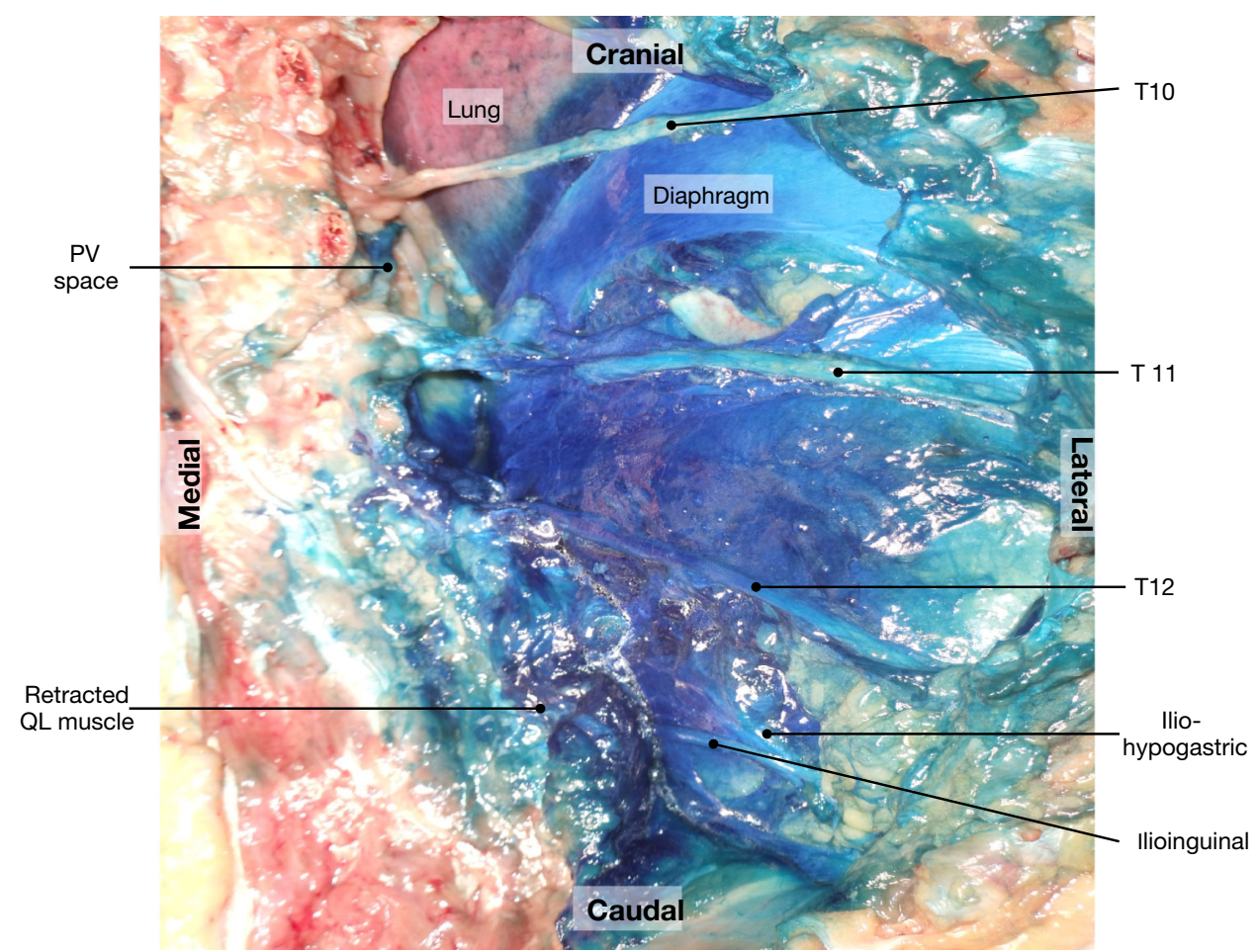

Patient management

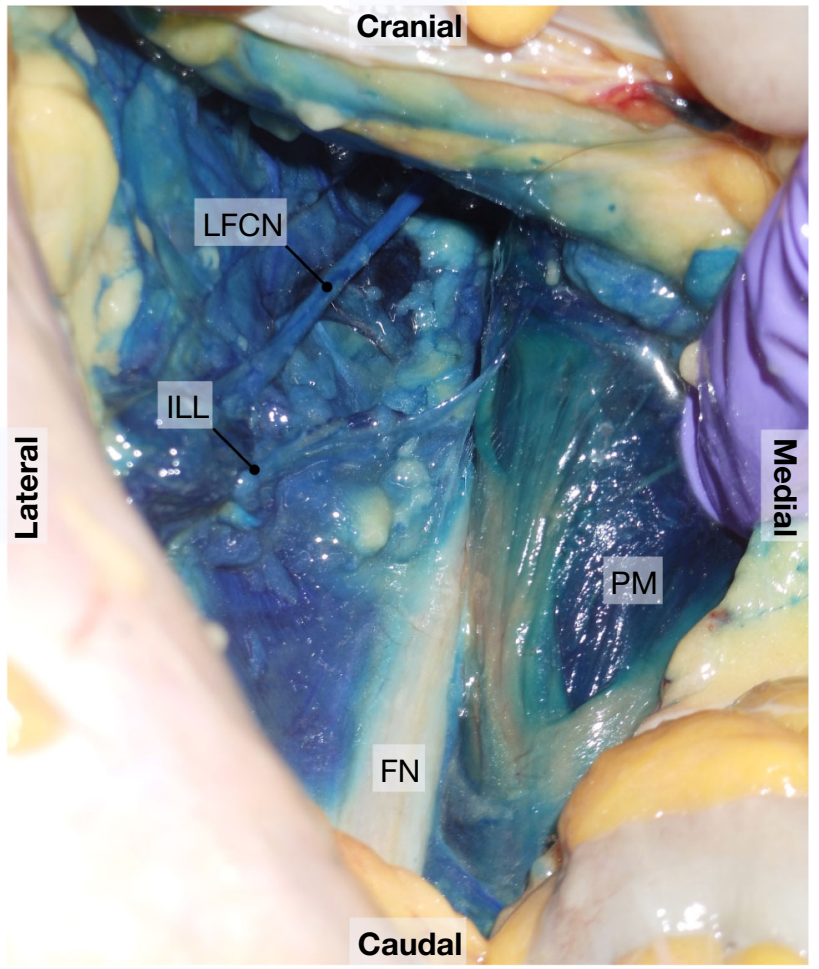

Fig. 6 Anterior view of cadaveric specimen following a left suprailiac anterior quadratus lumborum muscle $(\mathrm{QL})$ block. Dye staining can be seen on the femoral nerve (FN), the lateral cutaneous femoral nerve (LCFN), iliolumbar ligament (ILL), and the psoas major (PM) muscle
Five patients undergoing elective hip surgery under general anesthesia were prospectively recruited. Written informed consent for the performance of a supra-iliac anterior QL block was acquired from all patients. International guidance on data management and the Declaration of Helsinki principles were strictly adhered to. ${ }^{22}$ The QL blocks were performed in the Cleveland Clinic block room. Patients were monitored with electrocardiogram, noninvasive blood pressure, and pulse oximetry. Peripheral venous access was obtained, supplemental oxygen was supplied via nasal cannula, and midazolam 1-2 mg iv was injected for anxiolysis. Subsequently, a unilateral suprailiac anterior QL block with catheter insertion was performed using the technique described above (Figs 2 B, C).

Local anesthetic was infused through the peripheral nerve catheter during surgery to reduce intraoperative systemic analgesic requirement, and during the postoperative period via an ambulatory electronic infusion pump (Moog Curlin Infusion Pump, Salt Lake City, UT, USA). The regimen consisted of ropivacaine $0.2 \%$ infused at a rate of $8 \mathrm{~mL} /$ hour, with a patientcontrolled bolus of $12 \mathrm{~mL}$ every $60 \mathrm{~min}$ as needed during catheter analgesia. While the catheters remained in situ, neurologic assessment was performed every morning by the acute pain team and physical therapists, which included assessing sensory and motor involvement. The dermatomal 
Fig. 7 Posterior view of cadaveric specimen following a left supra-iliac anterior QL block. Dye staining can be seen to spread laterally and craniocaudally to involve the subcostal nerve (T12), the ilioinguinal and iliohypogastric nerves, and the anterior surface of the reflected QL muscle. QL = quadratus lumborum muscle; ILL = iliolumbar ligament

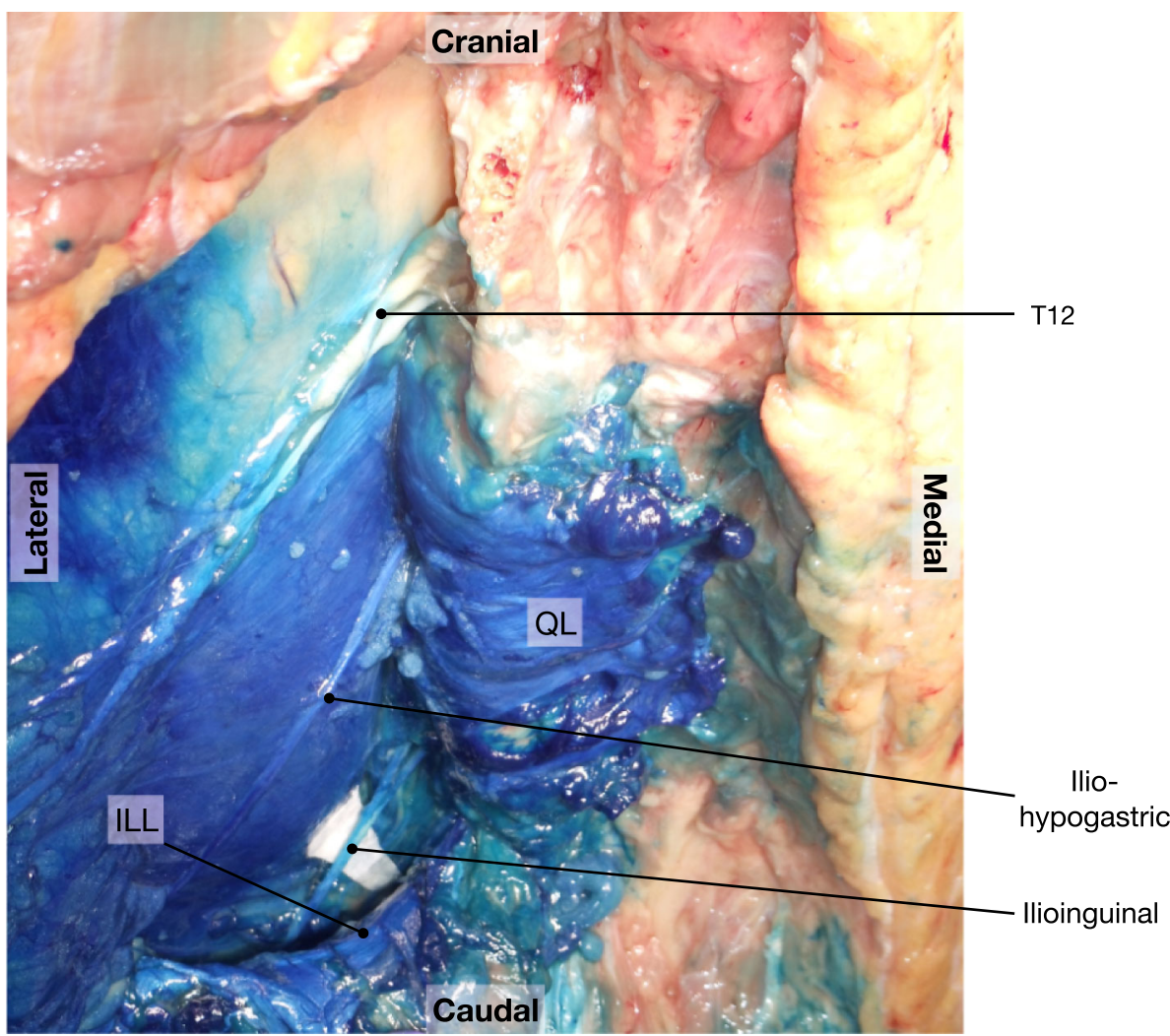

distribution of sensory loss was assessed with ice from the posterior axillary line to the midline, and across all areas of the lower limb. Motor strength was examined using the International Standards for Neurological Classification of Spinal Cord Injury. ${ }^{23}$ Motor assessment of hip flexion (L2), hip extension (L5, S1, S2) and knee extension (L2-L4), knee flexion (S1) was rated on a scale from $0-5$, with 0 representing no contraction, 3 representing movement against gravity but not to resistance, and 5 representing normal motor strength.

Data were obtained from the electronic medical records, including the extent of sensory dermatomal coverage (shown by a loss of cold sensation to ice), the duration of analgesia, and pain scores using the numerical rating scale (NRS) before and after the blocks were recorded. ${ }^{24} \mathrm{We}$ reported the NRS pain scores using a scale of 0-10 as one measurement that was taken once daily when the acute pain team visited the patient in the morning and documented at rest. The sensory level and motor strength were also assessed during the same visit. Baseline preoperative analgesic medication was unchanged postoperatively. Data were collected on standardized forms, and recorded anonymously into a Microsoft Excel 2016 (Microsoft Corp, Redmond, WA, USA) spreadsheet. Descriptive statistics were used to report the data quantitatively or qualitatively as indicated.

\section{Results}

\section{Cadavers}

Six cadavers were included in the study (three male, three female) with body mass indices that ranged from 28 to 44 $\mathrm{kg} \cdot \mathrm{m}^{-2}$. Bilateral supra-iliac anterior QL blocks were successfully performed in all six cadavers, yielding 12 specimens for examination. Dye staining of the anterior aspect of QL muscle was seen to extend cranially to its attachment to the $12^{\text {th }}$ rib and caudally to the iliac crest in all specimens. Cranial spread was apparent posterior to the arcuate ligaments of the diaphragm and reached the thoracic extra-pleural paravertebral gutters in ten $(83 \%)$ specimens, including staining of T10-T12 segmental thoracic nerve roots (Fig. 5); this paravertebral spread was absent in two specimens. Lateral spread to the transversus abdominis plane was only present in two (17\%) specimens.

Staining of the subcostal (T12), iliohypogastric, ilioinguinal, and lateral femoral cutaneous and femoral nerves was consistently seen in all specimens (Figs 6, 7). In addition, all 12 specimens showed staining of L1, L2, L 3 nerve roots, and in eight $(67 \%)$ specimens, the L4 nerve root was stained. Faint staining of the surrounding L5 contribution of the lumbosacral trunk and the obturator nerve was noted in two (17\%) specimens (Fig. 8). No 
specimens showed sacral nerve root staining (Table 1). We did not examine the epidural space for possible dye spread. Identification of the iliolumbar ligament was noted in two (17\%) specimens (Figs 6, 7). Identification of the lateral lumbosacral ligament was difficult in all cadavers.

\section{Patients}

Five patients received preoperative supra-iliac anterior QL blocks via peripheral nerve catheters, with an initial bolus of $25 \mathrm{~mL} 0.5 \%$ ropivacaine and continuous infusions. Patient demographics are presented in Table 2 and analgesic details in Table 3. All patients received general anesthesia with a supra-iliac anterior QL block and no other regional anesthetic intervention.

\section{Patient 1}

Following catheter insertion, right-sided sensory blockade to cold sensation from T10-L3 was shown, including femoral and lateral femoral cutaneous nerve distributions. Postoperatively, his baseline analgesic regimen was resumed. A T10-L3 sensory block to cold was consistently present on daily assessment by the acute pain team. The supra-iliac anterior QL catheter was removed on postoperative day (POD) 4 , and his pain

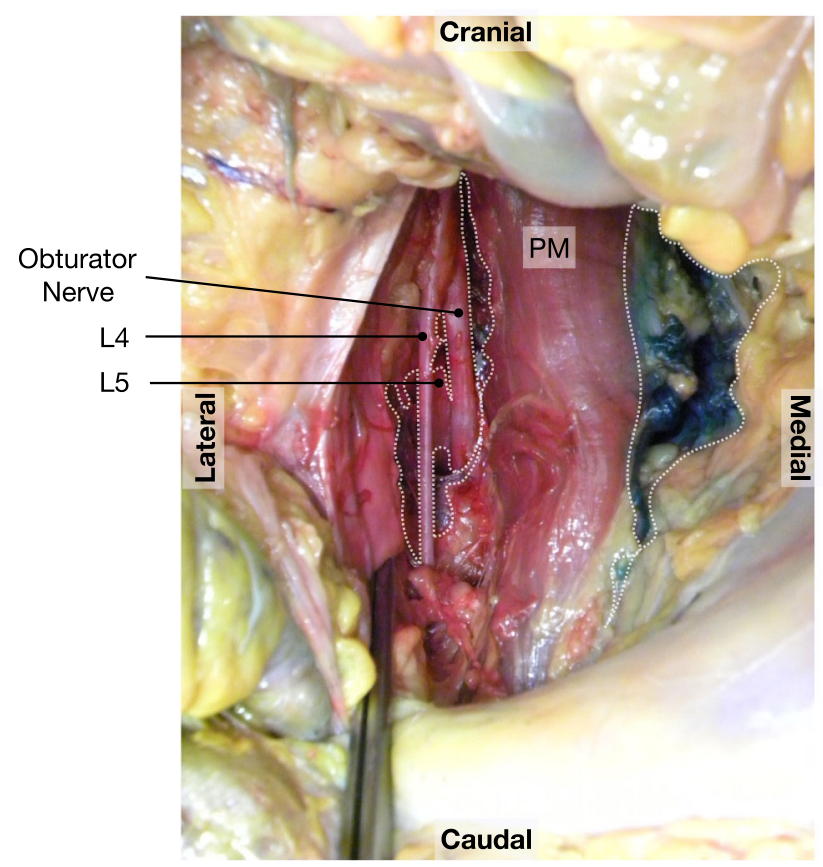

Fig. 8 Cadaveric specimen following a right supra-iliac anterior quadratus lumborum muscle (QL) block. Areas of dye staining are encircled with a white dotted line. Faint dye staining can be seen on the obturator nerve and L4 medial to the psoas major muscle (PM). L5 can be seen deep and medial to the obturator and L4 nerves, respectively score was 2 at rest. After $24 \mathrm{hr}$, the preoperative hip pain score was 5 . His pain scores at rest were 3,4 , and 3 on POD 2,3 , and 4 , respectively.

The patient continued on the same preoperative analgesic medication regimen and received three doses of fentanyl $50 \mu \mathrm{g} i v$ in the first $48 \mathrm{hr}$ for breakthrough pain. Motor strength was reduced to $3 / 5$ in right hip flexion and knee extension on the right side for the first $24 \mathrm{hr}$ following catheter insertion. At $48 \mathrm{hr}$ postoperatively, motor strength returned to $5 / 5$ throughout the lower limb without limiting ambulation and physiotherapy. He received a single dose of hydrocodone/acetaminophen 5/325 mg on day 4, two hours before the nerve catheter was removed.

\section{Patient 2}

A unilateral sensory block to cold was observed following catheter insertion from T9 to L4, and then a T10 to L3 sensory blockade level remained throughout the duration of local anesthetic infusion. Her home analgesic regimen was resumed in the immediate postoperative period. During the period of local anesthetic infusion, she reported NRS pain scores at the site of incision of 2 out of 10 at rest after the catheter was inserted. The NRS pain scores at the site of incision were 4, 3, 4 on POD 1, 2, and 3 respectively at rest. On POD 3, the dose of transdermal fentanyl was increased from $100 \mu \mathrm{g} \cdot \mathrm{hr}^{-1}$ to $125 \mu \mathrm{g} \cdot \mathrm{hr}^{-1}$. She also received one dose of oxycodone/acetaminophen $5 / 325 \mathrm{mg}$ before the catheter was removed. She required no additional breakthrough analgesics and was discharged on POD 4. Motor strength was reduced to $4 / 5$ in hip flexion and knee extension for the first $24 \mathrm{hr}$ following catheter insertion. Thereafter, motor strength returned to $5 / 5$ throughout with no limitation to patient ambulation and physiotherapy.

\section{Patient 3}

A unilateral sensory block to cold was observed following catheter insertion from T9-L4, and then a T10-L3 sensory blockade level remained throughout the duration of local anesthetic infusion. Her home analgesic regimen was resumed in the immediate postoperative period. During the period of local anesthetic infusion, she reported NRS pain scores at the site of incision of 4 out of 10 at rest, from her baseline pain scores of 8 . Her pain scores on POD 1 and 2 were 4 and 5, respectively. On POD 2, the catheter was injected with liposomal bupivacaine and then removed. This injection comprised $20 \mathrm{~mL}$ of liposomal bupivacaine, corresponding to $266 \mathrm{mg}$ (Exparel, Pacira Pharmaceuticals, Parsippany, NJ, USA) diluted with normal saline to $30 \mathrm{~mL}$. She had an additional $48 \mathrm{hr}$ of analgesia and dermatomal blockade after catheter removal without weakness. She 
Table 1 Frequency of dye staining of relevant nerves

\begin{tabular}{lll}
\hline Structure & $\begin{array}{l}\text { Number of specimens } \\
\text { demonstrating dye staining }(n)\end{array}$ & $\begin{array}{l}\text { Frequency of dye } \\
\text { staining (\%) }\end{array}$ \\
\hline $\begin{array}{l}\text { Subcostal (T12) } \\
\text { nerve }\end{array}$ & 12 & $100 \%$ \\
$\begin{array}{l}\text { Iliohypogastric } \\
\text { nerve }\end{array}$ & 12 & $100 \%$ \\
Ilioinguinal nerve & 12 & $100 \%$ \\
Lateral femoral & 12 & $100 \%$ \\
$\quad$ cutaneous & & \\
$\quad$ nerve & 12 & $100 \%$ \\
Femoral nerve & 12 & $17 \%$ \\
Obturator nerve & 2 & $100 \%$ \\
L1 nerve root & 12 & $100 \%$ \\
L2 nerve root & 12 & $100 \%$ \\
L3 nerve root & 12 & $67 \%$ \\
L4 nerve root & 8 & $17 \%$ \\
L5 nerve root & 2 & $0 \%$ \\
S1-S5 & 0 & $83 \%$ \\
Thoracic & 10 & \\
paravertebral & & \\
space & & \\
\hline
\end{tabular}

required hydromorphone $0.2 \mathrm{mg} i v$ two times every day in the first three days as breakthrough analgesics. Motor strength was reduced to $4 / 5$ in hip flexion and knee extension for the first $12 \mathrm{hr}$ following catheter insertion. Thereafter, motor strength returned to $5 / 5$ throughout with no limitation to patient ambulation and physiotherapy.

\section{Patient 4}

A unilateral sensory block to cold was observed from T10 L3 following catheter insertion, and then a sensory blockade from T11-L2 remained throughout the duration of local anesthetic infusion and for $36 \mathrm{hr}$ after catheter removal. Her home analgesic regimen was resumed in the immediate postoperative period. A bolus of $266 \mathrm{mg}$ liposomal bupivacaine $30 \mathrm{~mL}$ was administered through the catheter on POD 1 and then removed that same day because of concerns for catheter infection risk; purulent thick synovial fluid was collected intraoperatively with evidence of peri-prosthetic joint infection. She had an additional $36 \mathrm{hr}$ of analgesia and dermatomal blockade after catheter removal without weakness. Her home analgesic regimen was resumed in the immediate postoperative period with the addition of oxycontin 10 $\mathrm{mg}$ twice daily. She reported NRS pain scores at the site of incision between 2 and 4 out of 10 at rest. Motor strength remained at $5 / 5$ in hip flexion and knee extension after catheter insertion and bolus with liposomal bupivacaine.
There was no limitation to patient ambulation and physiotherapy.

\section{Patient 5}

A unilateral sensory block to cold was observed from T10 L4 following catheter insertion, and a T11-L3 sensory blockade was present throughout the duration of local anesthetic infusion. Her home analgesic regimen was resumed in the immediate postoperative period. Numerical rating scale pain scores at the site of incision were 3,4 , and 4 on POD 1, 2, and 3, respectively. Her catheter was removed on POD 3 before commencing heparin infusion. Motor strength was reduced to $4 / 5$ in hip flexion and knee extension for the first $12 \mathrm{hr}$ following catheter insertion. Thereafter, motor strength returned to $5 / 5$ throughout with no limitation to patient ambulation and physiotherapy.

The mean (standard deviation) duration of catheter infusion was 2.6 (1.1) days. No patients experienced any adverse events resulting from the blocks or catheters, including hypotension, fall, urinary retention, or bleeding or infection at the insertion site.

\section{Discussion}

This cadaveric study shows that the supra-iliac approach to anterior QL block leads to consistent involvement of branches of the lumbar plexus, including the femoral nerve, lateral femoral cutaneous nerve, ilioinguinal nerve, and iliohypogastric nerve. It also blocks the L1 nerve roots, thus could anesthetize the superior cluneal nerves that innervate the skin over the greater trochanter. Our clinical data are in keeping with our cadaveric findings, indicating that it can provide analgesia for hip surgery. Nevertheless, our cadaveric evidence and preliminary clinical experience showed inconsistent involvement of the L4 nerve root, minimal involvement of the L5 root and obturator nerve, and no involvement of the sacral plexus.

The fascial planes of the pelvis, posterior and lateral abdominal wall (including the psoas and QL muscles), and the thorax are all in continuity with each other at various access points ${ }^{25,26}$ and could potentially act as a conduit for local anesthetic injectate spread. ${ }^{27,28}$ As the branches of the lumbar plexus emerge from within the psoas major muscle at variable cranio-caudal levels, spread to these nerves is possible through the fascial plane scaffold of the posterior abdominal wall. ${ }^{25}$ This was shown in our investigations by clear staining of the upper branches of the lumbar plexus. Additionally, as the psoas fascia is in continuity with the transversalis fascia in the abdomen and the endothoracic fascia in the thorax beneath the medial and lateral arcuate ligaments as well as the aortic hiatus of the diaphragm, we 
Table 2 Demographic details of patients receiving supra-iliac quadratus lumborum block

\begin{tabular}{|c|c|c|c|c|c|}
\hline Patient & 1 & 2 & 3 & 4 & 5 \\
\hline Age (yr) & 85 & 63 & 54 & 49 & 57 \\
\hline Sex & M & $\mathrm{F}$ & $\mathrm{F}$ & $\mathrm{F}$ & $\mathrm{F}$ \\
\hline $\begin{array}{l}\text { BMI } \\
\qquad\left(\mathrm{kg} \cdot \mathrm{m}^{-2}\right)\end{array}$ & 23 & 30 & 29 & 38 & 22 \\
\hline $\begin{array}{l}\text { ASA physical } \\
\text { status }\end{array}$ & II & III & III & III & IV \\
\hline Comorbidities & $\begin{array}{l}\text { - Chronic hip and back } \\
\text { pain } \\
\text { - Cervical and lumbar } \\
\text { laminectomy }\end{array}$ & $\begin{array}{l}\text { - Chronic hip and back } \\
\text { pain } \\
\text { - OSA } \\
\text { - Fibromyalgia } \\
\text { - Depression } \\
\text { - Reflex sympathetic } \\
\text { dystrophy } \\
\text { - Multi-level lumbar } \\
\text { fusion } \\
\text { - Failed spinal cord } \\
\text { stimulator }\end{array}$ & $\begin{array}{l}\text { - Chronic hip pain } \\
\text { - COPD } \\
\text { - Liver failure } \\
\text { - Depression }\end{array}$ & $\begin{array}{l}\text { - Chronic hip pain } \\
\text { - Multiple hip surgery }\end{array}$ & $\begin{array}{l}\text { - Chronic hip pain } \\
\text { - Diabetes } \\
\text { - Peripheral neuropathy } \\
\text { - Peripheral vascular disease } \\
\text { (infra-renal aorto-iliac } \\
\text { occlusion) } \\
\text { - Avascular necrosis of the } \\
\text { hip }\end{array}$ \\
\hline $\begin{array}{l}\text { History of } \\
\text { chronic } \\
\text { pain }\end{array}$ & Yes & Yes & Yes & Yes & Yes \\
\hline $\begin{array}{l}\text { Baseline hip } \\
\text { pain score }\end{array}$ & $5 / 10$ & $7 / 10$ & NA & $7 / 10$ & $8 / 10$ \\
\hline $\begin{array}{l}\text { Baseline } \\
\text { analgesics }\end{array}$ & $\begin{array}{l}\text { - Oxycodone MR } 20 \mathrm{mg} \\
\text { BID } \\
\text { - Hydrocodone/ } \\
\text { acetaminophen 5/325 } \\
\text { mg BID PRN } \\
\text { - Gabapentin } 300 \mathrm{mg} \\
\text { OD } \\
\text { - Nortriptyline } 75 \mathrm{mg} \\
\text { QID } \\
\text { - Lorazepam } 0.5 \mathrm{mg} \text { TID }\end{array}$ & $\begin{array}{l}\text { - Oxycodone/ } \\
\text { acetaminophen 5/325 } \\
\text { mg q6hr PRN } \\
\text { - Fentanyl } 100 \mu \mathrm{g} \cdot \mathrm{hr}^{-1} \text {. } \\
\text { transdermal }\end{array}$ & $\begin{array}{l}\text { - Hydromorphone } 1 \\
\text { mg BID PRN } \\
\text { - Duloxetine } 20 \mathrm{mg} \\
\text { BID } \\
\text { - Fentanyl } 50 \\
\mu \mathrm{g} \cdot \mathrm{hr}^{-1} \text {. } \\
\text { transdermal }\end{array}$ & $\begin{array}{l}\text { - Oxycodone IR } 30 \\
\text { mg q3hr } \\
\text { - Gabapentin } 300 \mathrm{mg} \\
\text { BID } \\
\text { - Venlafaxine } 150 \mathrm{mg} \\
\text { OD } \\
\text { - Fentanyl } 50 \mu \mathrm{g} \cdot \mathrm{hr}^{-1} \text {. } \\
\text { transdermal }\end{array}$ & $\begin{array}{l}\text { - Oxycodone IR 5-10 mg } \\
\text { Q4h } \\
\text { - Oxycontin } 10 \mathrm{mg} \mathrm{ON} \\
\text { - Acetaminophen } 650 \mathrm{mg} \\
\text { TID } \\
\text { - Gabapentin } 600 \mathrm{mg} \text { TID }\end{array}$ \\
\hline $\begin{array}{l}\text { Operative } \\
\text { details } \\
\text { (Duration) }\end{array}$ & $\begin{array}{l}\text { Revision THA } \\
(4 \mathrm{hr} 20 \mathrm{~min})\end{array}$ & $\begin{array}{l}\text { Primary THA } \\
(2 \mathrm{hr} 44 \mathrm{~min})\end{array}$ & $\begin{array}{l}\text { Primary THA with } \\
\text { gluteus medius } \\
\text { repair } \\
\text { (2 hr } 53 \mathrm{~min})\end{array}$ & $\begin{array}{l}\text { Hip hardware removal } \\
\text { and placement of } \\
\text { spacer } \\
\text { (4 hr } 32 \mathrm{~min})\end{array}$ & $\begin{array}{l}\text { Primary THA } \\
(3 \mathrm{hr} 12 \mathrm{~min})\end{array}$ \\
\hline
\end{tabular}

$\mathrm{ASA}=$ American Society of Anesthesiologists; $\mathrm{BID}=$ bis in die; $\mathrm{BMI}=$ body mass index $; \mathrm{COPD}=$ chronic obstructive pulmonary disease; $\mathrm{F}=$ female; $\mathrm{M}=$ male; $\mathrm{MR}=$ modified release $\mathrm{NA}=$ not applicable; $\mathrm{OD}=$ once daily; OSA = obstructive sleep apnea; $\mathrm{PRN}=$ pro re nata; $\mathrm{QID}=$ quarter in die; TID = tri in die; THA = total hip arthroplasty; IR = immediate release; ON = once per day

were able to show spread to the lower thoracic paravertebral space. At the caudal end, the transversalis fascia is attached to the iliac crest and is less adherent in the sacral pelvic rim. ${ }^{29,30}$ Nonetheless, this may still produce a potential barrier to injectate spread from anterior to the QL muscle to the lumbosacral trunk and anterior rami of $\mathrm{S} 1-\mathrm{S} 3$.

In addition, the iliolumbar ligament is a thick ligament that traverses from the tip of the transverse process of the fifth lumbar vertebra to the posterior part of the inner lip of the iliac crest, forming a thickened lower border of the thoracolumbar fascia. As this ligament lies anterior to the $\mathrm{QL}$ muscle and posterior to the psoas muscle, it may be responsible for the limited caudal spread of injectate beyond L5. ${ }^{31}$

\section{Clinical context}

Three nerves principally innervate the hip: the femoral, obturator, and sciatic nerves. Cutaneous coverage for hip surgery also requires blockade of the lateral femoral cutaneous, iliohypogastric, the subcostal nerve, and the superior cluneal nerves, which primarily arise from the dorsal rami of $\mathrm{L}^{3} .^{32,33}$ Numerous regional anesthetic techniques have been used to provide analgesia following hip surgery, including intrathecal morphine, epidural 
Table 3 Analgesic details of patients receiving supra-iliac quadratus lumborum block

\begin{tabular}{|c|c|c|c|c|c|}
\hline Patient & 1 & 2 & 3 & 4 & 5 \\
\hline $\begin{array}{l}\text { Dermatomal coverage with } \\
\text { initial local anesthetic bolus }\end{array}$ & T1-L3 & T9-L4 & T11-L3 & T10-L3 & T10-L4 \\
\hline Intraoperative analgesic use & Fentanyl $300 \mu \mathrm{g}$ & $\begin{array}{l}\text { Fentanyl } 100 \mu \mathrm{g} \\
\text { Hydromorphone } \\
0.8 \mathrm{mg} \\
\text { Ketamine } 40 \mathrm{mg}\end{array}$ & $\begin{array}{l}\text { Fentanyl } 250 \mu \mathrm{g} \\
\text { Hydromorphone } \\
1 \mathrm{mg} \\
\text { Ketorolac } 30 \mathrm{mg} \\
\text { Lidocaine infusion } 1 \\
\mathrm{mg} \cdot \mathrm{kg}^{-1} \mathrm{hr}^{1}\end{array}$ & $\begin{array}{l}\text { Fentanyl } 100 \mu \mathrm{g} \\
\text { Hydromorphone } \\
1.2 \mathrm{mg}\end{array}$ & $\begin{array}{l}\text { Fentanyl } 300 \mu \mathrm{g} \\
\text { Hydromorphone } \\
\quad 0.4 \mathrm{mg}\end{array}$ \\
\hline $\begin{array}{l}\text { Dermatomal coverage with } \\
\text { catheter infusion of local } \\
\text { anesthetic }\end{array}$ & T10-L3 & T10-L3 & T10-L3 & T11-L2 & T11-L3 \\
\hline $\begin{array}{l}\text { Mean NRS at rest on POD 1, 2, } \\
3 \text {, and } 4^{\text {a }}\end{array}$ & $2,3,4,3$ & $4,3^{\mathrm{b}}, 4$ & 4,5 & $3^{\mathrm{b}}, 3$ & $3,4,4$ \\
\hline $\begin{array}{l}\text { Motor strength with initial } \\
\text { local anesthetic bolus }\end{array}$ & $3 / 5$ & $4 / 5$ & $4 / 5$ & $5 / 5$ & $4 / 5$ \\
\hline $\begin{array}{l}\text { Motor strength with catheter } \\
\text { infusion of local anesthetic }\end{array}$ & $5 / 5$ & $5 / 5$ & $5 / 5$ & $5 / 5$ & $5 / 5$ \\
\hline $\begin{array}{l}\text { Breakthrough analgesic } \\
\text { requirements }\end{array}$ & $\begin{array}{l}\text { Fentanyl } 50 \mu \mathrm{g} i v \\
\times 3 \mathrm{in} \text { the first } \\
48 \mathrm{hr}\end{array}$ & $\begin{array}{l}\text { Morphine } 2 \mathrm{mg} \mathrm{iv} \times \\
5 \mathrm{in} \text { the first } 48 \mathrm{hr}\end{array}$ & $\begin{array}{l}\text { Hydromorphone } 0.2 \mathrm{mg} \\
\text { iv } \times 6 \text { in the first } 3 \\
\text { days }\end{array}$ & $\begin{array}{l}\text { Fentanyl } 50 \mu \mathrm{g} i v \\
\times 5 \mathrm{in} \text { the first } \\
48 \mathrm{hr}\end{array}$ & $\begin{array}{l}\text { Fentanyl } 50 \mu \mathrm{g} i v \\
\times 2 \mathrm{in} \text { the first } \\
48 \mathrm{hr}\end{array}$ \\
\hline
\end{tabular}

NRS scores are mean scores measured after block while catheter in place, dermatomal levels are average daily dermatomal levels, motor strength assessments were of hip extension (L5, S1, S2) knee flexion (S1) motor strength in patients. NRS = numerical rating score; POD = postoperative day. ${ }^{a}$ NRS pain scores out of ten for days under acute pain follow-up; ${ }^{b}$ Liposomal bupivacaine injected then catheter removed

analgesia, fascia iliaca block, lumber plexus block, sacral plexus block, and local infiltration analgesia. ${ }^{34,35}$ Although effective, the popularity of epidural analgesia has declined because of its side-effect profile. ${ }^{36}$ Fascia iliaca blocks, though low-risk and simple to perform, have not shown significant analgesic efficacy compared with controls. ${ }^{37}$

Lumbar and sacral plexus blocks are challenging to perform and carry the risk of subarachnoid or epidural spread, hematoma, intravascular injection, and nerve injury. ${ }^{35,38}$ Local infiltration analgesia has shown shortterm analgesic value. ${ }^{39}$

To date, most published data regarding the QL block allude to its clinical utility for abdominal surgery. Several reports have been published regarding anterior QL block for analgesia following hip surgery, ${ }^{16,40,41}$ but these reports have low internal validity. A single randomized-controlled trial has shown superiority for the single-shot lateral QL block approach compared with femoral nerve block in hip fracture surgery. ${ }^{42}$ Two cadaveric studies have shown that an anterior QL block at the L3-L4 level can produce dye staining of L1-L3 nerve roots and the lower branches of the lumbar plexus. ${ }^{17,18}$ Dam et $a l^{28}$ and Elsharkawy et $a l .{ }^{43}$ on the other hand, did not observe direct lumbar plexus involvement within the psoas major muscle with an anterior QL block performed at a more cranial level point of injection than the supra-iliac technique we used. Based on previous cadaveric studies, ${ }^{28,43}$ the anterior QL block injectate may spread to the lumbar nerve roots and branches in addition to the lower thoracic paravertebral space (available as Electronic Supplementary Material [ESM] eTable 1).

The different approaches of the anterior QL block (subcostal, transverse, supra-iliac) are injections in the same tissue plane but at different cranio-caudal levels, and this can lead to differences in the LA spread, which is compounded by subtle differences in the tissue layers.

This illustrates that the exact vertebral level of injection within a fascial plane may determine the pattern of spread that is achieved. The current study agrees with Dam et al. ${ }^{28}$ and Elsharkawy et al. $^{43}$ in that there is spread to the paravertebral space, but the lower injection point we utilized in this study was associated with limited cranial spread. In addition, this study supports the previously published data demonstrating involvement of the subcostal (T12), iliohypogastric nerve, and ilioinguinal nerve $\mathrm{e}^{7,28,43}$ (ESM, eTable).

The anterior supra-iliac QL block may offer theoretical safety advantages over techniques such as the lumbar plexus and suprasacral parallel shift blocks. ${ }^{38}$ As the block target is a fascial plane rather than specific nerve per se, it eliminates the need for a nerve stimulator and minimizes the risk of mechanical nerve injury. In addition, the endpoint for needle insertion is more superficial, which reduces the risk of bleeding from unrecognized blood vessels; the lateral entry also reduces the risk of neuraxial spread of injectate. Cadaveric evidence may not always 
reflect clinical results; hence, we correlated our cadaveric findings with block performance in a small number of patients.

The supra-iliac anterior QL block is unlikely to provide surgical anesthesia or complete regional analgesia for hip surgery as this would require lumbar and sacral plexi blockade. Nevertheless, it may represent an alternative technique for hip analgesia, and its efficacy needs to be confirmed in adequately powered, well-designed, prospective randomized-controlled trials.

Our study does have limitations. We did not place catheters in cadavers and the initial injectate volume in cadavers was $5 \mathrm{~mL}$ higher, which could result in variable dermatomal spread between cadavers and the patients. This lower volume used in patients was essential to limit the total delivered dose, which was not a consideration in the cadavers. Although the anatomical dissection was meticulously performed to reduce the risk of artefactual dye spread during dissection, this cannot be completely excluded. Another limitation is that the sonographic visualization of the iliopsoas muscle from a supra-iliac window is challenging because of its retroperitoneal location and the acoustic shadow of the iliac crest. Nevertheless, localizing the cranial extension of the space between psoas and iliacus muscles is amenable to ultrasound visualization at the L5 level. The supra-iliac anterior QL block results in dye distribution to the lumbar plexus resulting in delayed mobilization and perioperative falls. Nevertheless, we did not see these complications in our small cohort.

One further potential limitation is that there is a $20 \%$ incidence of anatomical variation in the route taken by individual nerves from the lumbar plexus, ${ }^{44}$ although this was not observed in our anatomical dissections. Nevertheless, although precise localization of the nerves may vary, the interfascial planes they travel through are predictable; therefore, the utility of an interfascial plane block technique might be unaffected by this variation. ${ }^{45}$ Additionally, we did not specifically dissect the lumbar epidural space to see if dye had spread to there, which may be a possible mechanism for the observed analgesia. Finally, there was heterogeneity in the baseline analgesic requirements and the severity of chronic pain in included patients, and no control group was investigated. Moreover, the retrospective nature of the data is subject to the common pitfalls of retrospective analyses. Therefore, our finding should be interpreted as hypothesis-generating only. Future randomized-controlled studies are needed to evaluate the effectiveness of this technique and its comparative effectiveness $v s$ other techniques in clinical care.

\section{Conclusion}

This cadaveric study and patient series shows that a suprailiac approach to the anterior QL block likely produces T10-L3 dermatomal coverage, but no sacral plexus involvement or injectate distribution below L5. This technique may have clinical utility for analgesia in hip surgery.

Conflict of interest Dr. Elsharkawy has received unrestricted educational funding from PAJUNK (GA, USA), and is a consultant for PACIRA (Troy Hills, NJ, USA). Those companies had no input into any aspect of the present project design or manuscript preparation. The other authors declare no conflicts of interest.

Editorial responsibility This submission was handled by Dr. Hilary P. Grocott, Editor-in-Chief, Canadian Journal of Anesthesia.

Author contributions Hesham Elsharkawy, Ki Jinn Chin, and Kariem El-Boghdadly contributed substantially to all aspects of this manuscript, including study conception and design, acquisition, analysis, and interpretation of data, and drafting the article. Theresa $J$. Barnes contributed substantially to the conception and design of the manuscript. Richard Drake contributed substantially to the acquisition of data. Kamal Maheshwari, and Jean-Louis Horn contributed to the analysis of data. Loran Mounir Soliman contributed substantially to the interpretation of data.

Funding Departmental funding.

\section{References}

1. El-Boghdadly K, Elsharkawy H, Short A, Chin KJ. Quadratus lumborum block nomenclature and anatomical considerations. Reg Anesth Pain Med 2016; 41: 548-9.

2. Blanco R. TAP block under ultrasound guidance: the description of a "no pops" technique: 271. Reg Anesth Pain Med 2007; 32: 130.

3. Blanco R, McDonnell JG. Optimal point of injection: the quadratus lumborum type I and II blocks. Available from URL: http://www.respond2articles.com/ANA/forums/post/1550.aspx (accessed December 2018).

4. Børglum J, Moriggl B, Jensen K, et al. Ultrasound-guided transmuscular quadratus lumborum blockade - 2013 Available from URL: https://academic.oup.com/bja/article/doi/10.1093/bja/ el_9919/2451466 (accessed December 2018).

5. Kadam VR. Ultrasound-guided quadratus lumborum block as a postoperative analgesic technique for laparotomy. J Anaesthesiol Clin Pharmacol 2013; 29: 550-2.

6. Kadam VR. Ultrasound guided quadratus lumborum block or posterior transversus abdominis plane block catheter infusion as a postoperative analgesic technique for abdominal surgery. $\mathrm{J}$ Anaesthesiol Clin Pharmacol 2015; 31: 130-1.

7. Shaaban M, Esa WA, Maheshwari K, Elsharkawy H, Soliman $L M$. Bilateral continuous quadratus lumborum block for acute postoperative abdominal pain as a rescue after opioid-induced respiratory depression. A A Case Rep 2015; 5: 107-11. 
8. Visoiu M, Yakovleva N. Continuous postoperative analgesia via quadratus lumborum block - an alternative to transversus abdominis plane block. Paediatr Anaesth 2013; 23: 959-61.

9. Murouchi T, Iwasaki S, Yamakage M. Quadratus lumborum block: analgesic effects and chronological ropivacaine concentrations after laparoscopic surgery. Reg Anesth Pain Med 2016; 41: 146-50.

10. Baidya DK, Maitra S, Arora MK, Agarwal A. Quadratus lumborum block: an effective method of perioperative analgesia in children undergoing pyeloplasty. J Clin Anesth 2015; 27: 6946.

11. Chakraborty A, Goswami J, Patro V. Ultrasound-guided continuous quadratus lumborum block for postoperative analgesia in a pediatric patient. A A Case Rep 2015; 4: 34-6.

12. Elsharkawy H. Quadratus lumborum block with paramedian sagittal oblique (subcostal) approach. Anaesthesia 2016; 71: 2412.

13. La Colla L, Uskova A, Ben-David B. Single-shot quadratus lumborum block for postoperative analgesia after minimally invasive hip arthroplasty: a new alternative to continuous lumbar plexus block? Reg Anesth Pain Med 2017; 42: 125-6.

14. La Colla L, Ben-David B, Merman R. Quadratus lumborum block as an alternative to lumbar plexus block for hip surgery: a report of 2 cases. A A Case Rep 2017; 8: 4-6.

15. Hockett MM, Hembrador S, Lee A. Continuous quadratus lumborum block for postoperative pain in total hip arthroplasty: a case report. A A Case Rep 2016; 7: 129-31.

16. Ohgoshi $Y$, Nakayama H, Kubo EN, Izawa H, Kori S, Matsukawa $M$. Clinical experiences of the continuous quadratus lumborum block via paramedian sagittal oblique approach. J Clin Anesth 2017; 38: 89-90.

17. Carline L, Mcleod GA, Lamb C. A cadaver study comparing spread of dye and nerve involvement after three different quadratus lumborum blocks. Br J Anaesth 2016; 117: 387-94.

18. Adhikary SD, El-Boghdadly $K$, Nasralah Z, Sarwani N, Nixon $A M$, Chin KJ. A radiologic and anatomic assessment of injectate spread following transmuscular quadratus lumborum block in cadavers. Anaesthesia 2017; 72: 73-9.

19. Sondekoppam $R V$, Ip $V$, Johnston $D F$, et al. Ultrasound-guided lateral-medial transmuscular quadratus lumborum block for analgesia following anterior iliac crest bone graft harvesting: a clinical and anatomical study. Can J Anesth 2018; 65: 178-87.

20. Torres GM, Cernigliaro JG, Abbitt PL, et al. Iliopsoas compartment: normal anatomy and pathologic processes. Radiographics 1995; 15: 1285-97.

21. Van Dyke JA, Holley HC, Anderson SD. Review of iliopsoas anatomy and pathology. Radiographics 1987; 7: 53-84.

22. World Medical Association. World Medical Association Declaration of Helsinki: ethical principles for medical research involving human subjects. JAMA 2013; 310: 2191-4.

23. Kirshblum SC, Burns SP, Biering-Sorensen F, et al. International standards for neurological classification of spinal cord injury (revised 2011). J Spinal Cord Med 2011; 34: 535-46.

24. Hjermstad MJ, Fayers PM, Haugen DF, et al. Studies comparing numerical rating scales, verbal rating scales, and visual analogue scales for assessment of pain intensity in adults: a systematic literature review. J Pain Symptom Manage 2011; 41: 1073-93.

25. Willard FH, Vleeming A, Schuenke MD, Danneels L, Schleip R. The thoracolumbar fascia: anatomy, function and clinical considerations. J Anat 2012; 221: 507-36.

26. Frias Vilaça A, Reis AM, Vidal IM. The anatomical compartments and their connections as demonstrated by ectopic air. Insights Imaging 2013; 4: 759-72.

27. Wilke J, Krause F, Vogt L, Banzer W. What is evidence-based about myofascial chains: a systematic review. Arch Phys Med Rehabil 2016; 97: 454-61.
28. Dam M, Moriggl B, Hansen CK, et al. The pathway of injectate spread with the transmuscular quadratus lumborum block: a cadaver study. Anesth Analg 2017; 125: 303-12.

29. Steinbach LS, Schneider R, Goldman AB, Kazam E, Ranawat CS, Ghelman $B$. Bursae and abscess cavities communicating with the hip. Diagnosis using arthrography and CT. Radiology 1985; 156: 303-7.

30. Schmidt CK, Iwanaga J, Yilmaz E, Wilson C, Oskouian RJ, Tubbs $R S$. Absence of the lumbosacral trunk. Cureus 2017; 9: e1809.

31. Rucco V, Basadonna PT, Gasparini D. Anatomy of the iliolumbar ligament: a review of its anatomy and a magnetic resonance study. Am J Phys Med Rehabil 1996; 75: 451-5.

32. Lu J, Ebraheim NA, Huntoon M, Heck BE, Yeasting RA. Anatomic considerations of superior cluneal nerve at posterior iliac crest region. Clin Orthop Relat Res 1998; 347: 224-8.

33. Maigne $J Y$, Lazareth $J P$, Surville $H G$, Maigne $R$. The lateral cutaneous branches of the dorsal rami of the thoraco-lumbar junction. An anatomical study on 37 dissections. Surg Radiol Anat 1989; 11: 289-93.

34. Grant $C R$, Checketts $M R$. Analgesia for primary hip and knee arthroplasty: the role of regional anaesthesia. Continuing Educ Anaesth Crit Care Pain 2008; 8: 56-61.

35. Hojer Karlsen AP, Geisler A, Petersen PL, Mathiesen O, Dahl $J B$. Postoperative pain treatment after total hip arthroplasty: a systematic review. Pain 2015; 156: 8-30.

36. Jules-Elysee KM, Goon AK, Westrich GH, et al. Patientcontrolled epidural analgesia or multimodal pain regimen with periarticular injection after total hip arthroplasty: a randomized, double-blind, placebo-controlled study. J Bone Joint Surg Am 2015; 97: 789-98

37. Shariat AN, Hadzic A, Xu D, et al. Fascia iliaca block for analgesia after hip arthroplasty: a randomized double-blind, placebo-controlled trial. Reg Anesth Pain Med 2013; 38: 201-5.

38. Bendtsen TF, Pedersen EM, Haroutounian $S$, et al. The suprasacral parallel shift vs lumbar plexus blockade with ultrasound guidance in healthy volunteers-a randomised controlled trial. Anaesthesia 2014; 69: 1227-40.

39. Carthy D, Iohom $G$. Local Infiltration analgesia for postoperative pain control following total hip arthroplasty: a systematic review. Anesthesiol Res Pract 2012; 2012: 709531.

40. Johnston DF, Sondekoppam RV. Continuous quadratus lumborum block analgesia for total hip arthroplasty revision. J Clin Anesth 2016; 35: 235-7.

41. Ueshima $H$, Yoshiyama S, Otake $H$. The ultrasound-guided continuous transmuscular quadratus lumborum block is an effective analgesia for total hip arthroplasty. J Clin Anesth 2016; 31: 35 .

42. Parras T, Blanco R. Randomised trial comparing the transversus abdominis plane block posterior approach or quadratus lumborum block type I with femoral block for postoperative analgesia in femoral neck fracture, both ultrasound-guided (Spanish). Rev Esp Anestesiol Reanim 2016; 63: 141-8.

43. Elsharkawy $\mathrm{H}$, El-Boghdadly $K$, Kolli $S$, et al. Injectate spread following anterior sub-costal and posterior approaches to the quadratus lumborum block: a comparative cadaveric study. Eur J Anaesthesiol 2017; 34: 587-95.

44. Anloague PA, Huijbregts P. Anatomical variations of the lumbar plexus: a descriptive anatomy study with proposed clinical implications. J Man Manip Ther 2009; 17: e107-14.

45. Elsharkawy H, Pawa A, Mariano E. Interfascial plane blocks: back to basics, daring discourse. Reg Anesth Pain Med 2018; 43: 341-6.

Publisher's Note Springer Nature remains neutral with regard to jurisdictional claims in published maps and institutional affiliations. 